\title{
The Viability of Comparative Research Concept as a Paradigm for Decolonising Educational \\ Leadership Theory and Practice
}

\author{
Jean Pierre Elonga Mboyo \\ Teesside University, Middlesbrough, United Kingdom
}

\begin{tabular}{lr}
\hline Abstract & $\begin{array}{r}\text { Article } \\
\text { Info }\end{array}$ \\
\hline The dominance of Western research methodologies and & $\begin{array}{r}\text { Article } \\
\text { History: } \\
\text { epistemologies has come under intense scrutiny. However, the }\end{array}$ \\
recognition that knowledge is produced and packaged differently & $\begin{array}{r}\text { Received } \\
\text { cannot override its fluid, unbounded and comparative nature. }\end{array}$ \\
$\begin{array}{lr}\text { That said, researchers are yet to outline the case for a decolonising } \\
\text { comparative educational leadership knowledge base. This first }\end{array}$ & $\begin{array}{r}\text { Accepted } \\
\text { September }\end{array}$ \\
linked article, therefore, introduces 'comparative research concept' & 22,2020 \\
(CRC) as a viable paradigm to navigate ontological, & Keywords: \\
epistemological, and cultural messiness when carrying out cross- & Comparative \\
context (educational leadership) research. In particular, the article & research concept, \\
discusses and provides a repertoire of arguments on how CRC can & educational \\
be operationalised through a narrative research approach that & leadership, \\
cultivates difference out of amalgamation and vice versa through & Decolonisation, \\
given research methods, constituencies and analytical Narrative approach & \\
perspectives. & \\
\hline Cited as: &
\end{tabular}

\section{Cited as:}

Elonga Mboyo, J.P. (2021). The viability of comparative research concept as a paradigm for decolonising educational leadership theory and practice. Research in Educational Administration \& Leadership, 6(3), 554584. DOI: $10.30828 / \mathrm{real} / 2021.3 .2$ 


\section{Introduction}

Colonisation is regarded as a turning point heralding an imperial project that systematically sought to foreground Euro-centric mono-cultural perceptions of reality, knowledge and methodology on the African continent and around the world. This, arguably, on-going 'incursion into the mind' (Samier, 2017) leading to an 'epistemicide' (Khalifa et al., 2018, p. 8) undermines the importance of context (Harris \& Jones, 2017) and the plurality of epistemologies (Tesar \& Arndt, 2017) that are not, in themselves, immune to 'the reality of locally engineered tyrannies' (Elonga Mboyo, 2018, p. 122). Although the recent upsurge in educational studies in Africa, particularly in the area of leadership and management, may constitute an encouraging exercise of reclaiming lost ground and overturning the Eurocentric ideology of domination, Hallinger's (2018, pp. 374-375) initial systematic review does 'not seek to synthesize substantive findings reported in [his] corpus of [selected] studies'. The subsequent systematic review (Hallinger, 2019) of South African dominant literature on school leadership on the African continent highlights a focus on normative and traditional themes, such as shared, instructional and transformational leadership, among others, while noting the need to develop quantitative conceptual research models in order to yield more conclusive claims. While quantitative and qualitative methodologies are as important and the superiority of one over the other should be relaxed (Punch \& Oancea, 2014), the conclusiveness of a more potent decolonising ontological and epistemological nature of the body of educational leadership knowledge to be developed is equally important. Scholars are, however, divided on which approach to take. Dixon (1977), for example, has argued for clear-cut and incommensurable ontologies, 
epistemologies, methodologies between the northern and southern hemispheres. Smith (1999), instead, does not see decolonisation as a rejection of Western notions. These stances can be reframed through the territorial, sentimental, symbolic and instrumental approaches to leadership and management research in Africa as uniquely discussed by Zoogah and Nkomo (2013).

The territorial approach aims to advance a uniquely different and bounded (African) stance to leadership and management. Khalifa et al.'s (2018) review highlights some distinctively indigenous ways of leading schools and adds to a territorial educational leadership chorus that more or less exclusively explores how the 'socio-cultural context of African education impacts leadership, management and school processes' (Hallinger, 2018, p. 371).

The sentimental approach seeks to underline the similarities while overlooking the differences with Western approaches. The symbolic frame is not concerned with a unique approach and emphasises neither African nor Western/ global identities. Arguably, the unfiltered expansion and acceptance of enduring western theoretical and methodological orthodoxy lend themselves to both the sentimental and symbolic approaches and consequently not viable decolonising strands of educational leadership research and practice.

The instrumental approach, recommended by Zoogah and Nkomo (2013), differs from Ribbins and Gunter's (2002) instrumental knowledge domain which is concerned with transferable tried and tested educational leadership knowledge. Zoogah and Nkomo's reading of instrumental approach concurs with Smith's (1999) view on some degree of compatibility between indigenous and non-indigenous knowledge and is the focus of these initial linked articles of the special issue, which seek to do much more than juxtaposing territorial 
research approaches in order to compare and contrast both the differences and similarities in research and leadership practices in Africa and outside of it. A theorised synthesis of trends emerging from an empirical comparative educational leadership research carried out in both northern and southern hemisphere contexts will be given in the second linked article. Before then, a clear comparative conceptual framework outlining methodological hybridisation capable of eliciting indigenous cultural and educational values and approaches (Poloma \& Szelényi, 2018) is required. In other words, the case for researching 'the cultural preferences and practices of some [my italics] African people' (Higgs, 2012, p. 37) and some [my italics] European ones, for example, in a single comparative research project needs to be made to validate the place of cross-context comparative or instrumental educational leadership knowledge. Here, outright rejection and dismantling of (un)documented historical systems that perpetuate dominance is not the starting point but rather a possible outcome among other discernible possibilities following contextual ontological, epistemological and cultural analysis of unique but non-impervious contexts.

This initial linked article, therefore, I attempt to coin and discuss in the next section 'comparative research concept' (CRC) as a methodological paradigm to foreground the development, in the second linked article, of a cross-context (northern and southern hemispheres) comparative educational leadership theory and practice framework drawn from empirical research. As already stated, this is a legitimate decolonising approach in the sense argued by Smith (1999), where Western notions are not rejected but configured with local ones in a way that brings out and recognises contextual differences emerging from shared commonalities and vice versa. Individually and/ or together, the two linked articles will form the basis for 
contributions from other invited scholars whose commentaries and/ or empirical research input on not only the volume but also the nature of decolonising educational leadership knowledge and practice may (or not) fall within different approaches, as outlined by Zoogah and Nkomo (2013), and particularly the one chartered by this first linked article. That said, the rest of this first linked article explores key ontological, epistemological and cultural features of CRC as paradigm and specifically discusses narrative as a possible research approach alongside consistent methods, composition of research constituents and analytical processes.

\section{Comparative Research Concept (CRC): A Paradigm}

Decolonising studies, that do not necessarily have to reject Western notions (Smith, 1999), require a philosophical and conceptual approach of a paradigmic shift beyond binaries particularly for international and comparative purposes (paraphrasing Simier, 2017 cited in Crosley and Watson, 2003; Dabashi, 2013). This section, therefore, discusses what is understood by CRC paradigm by defining it and exploring how a CRC researcher can navigate through compartmentalisation of ontology, epistemology, and culture that not only impounds knowledge but also fails to recognise inherent amalgamation that the decolonising exercise must creatively engage with, particularly in cross-context comparative research, without compromising the singularity of context and run the risk of neocolonisation.

\section{What is CRC?}

CRC is a philosophical and methodological worldview, mindset or paradigm (Kuhn, 1962) that looks beyond compartmentalisation in order to remain open to various possibilities including the amalgamation of ontologies, epistemologies, methods, analyses and 
research outcomes: multiple perspectives. Viewed in this way, CRC bears some resemblance to Denzin and Lincoln's (2000) bricolage, which 'signifies interdisciplinary' (Kincheloe, 2001, p. 680). This is the case if one considers the view that, like bricolage, CRC is multiperspectival, cultivates difference in both methods of inquiry and philosophical notions that, in turn, shape our worldviews. Although different as shall be explored below, but like CRC, bricolage argues for research to be an elastic (shifting) conversation that opens knowledge possibilities rather than promoting procedural rigidity to suit specific contexts.

While CRC is all of the above, it is different from bricolage in the sense that the latter has had to overcome the charge of being superficial and devoid of bases for specialised knowledge production (Kinchelo, 2001). CRC, on the contrary, departs from the depth of multiple ontologies and epistemologies in order to generate context specific approaches to engaging (with) reality. Inclusivity and divergence are two key characteristics to bear in mind when thinking about CRC. Its doctrine arguably centres on promoting the (inevitable) way of being in (ontology), knowing the (epistemology) and engaging with (methods) the world that is based on creating shifts (Springgay \& Truman, 2017) that unify in order to triangulate binaries and plant/ identify differences in unique decolonising authorship of contextual school leadership theories and practices. In cross-context studies then, $\mathrm{CRC}$ is not a choice to eschew but an obligatory research exercise that is based on shifts and perspectives, the validity of which must be defended. A broad range of ontological, epistemological and cultural arguments that align with CRC can then be developed. 


\section{How Can a CRC Researcher Frame Ontology?}

Ontology 'is the philosophical study of the nature of existence or reality, of being or becoming, as well as the basic categories of things that exist and their relations' (Kivunja \& Kuyini, 2017). To grasp ontology within CRC paradigm, one has to consider how ontology has been framed thus far. Reviews of organisational literature (Slawecki, 2018 based on Burrell \& Mogran, 1979; Guba \& Lincoln 2005), educational leadership literature (Brundrett \& Rhodes, 2014; Grogan \& Simmons, 2012; Ribbins \& Gunter, 2002) and the wider body of educational research (Creswell, 2009) have documented a variety of single research traditions or paradigms that produce single knowledge domains. These different traditions have well defined and, arguably, incommensurable ontological assumptions (Denzin \& Lincoln, 2005) that researchers need to know and apply in their empirical studies.

Educational (leadership) researchers involved in cross-context studies can overcome the above ontological compartmentalisation by drawing on insights from, for example, critical realist traditions (Bhaskar, 1989), relational sociology (Eacott, 2019), methodology of Ubuntu (Elonga Mboyo, 2016) and even integral psychology (Jaroken, 2009). In an effort to overcome ontological binaries, critical realist depth ontology (Bhaskar, 1989) stratifies reality that can be reflected in different layers of education policies that can move from being objectively internationalised to being subjectively experienced in different contexts. The causality principle in critical realism can also be flipped and framed through the (in)completion criteria within nuanced critical realism ontological thinking (Elonga Mboyo, 2019a; 2019b). Eacott's (2019) relational approach also seeks to overcomes ontological binaries by focusing more on agents' or auctors' ability to generate spatio-temporal conditions through organising activity. Jaroken's (2009) integral theory is another viale ontological possibility. İt not 
only recognises but also combines the validity of diverse zones of being and by implication of knowing which are objective, inter-objective, subjective and inter-subjective.

These possibilities for overcoming ontological compartmentalisation are not without critics one of which being the suggestions that they are dominated by theorists from the northern hemisphere and, despite their multi-perspectival stance, could be seen by those in the south as non-indigenous and, therefore, territorial. The contentious claim of the lack of a coherent African-based sociological worldview (Carroll, 2014), let alone a comparative one, should not mean attempts are not being made to that end. Although communalism is foregrounded as a distinctively defining feature of African social reality, Letsheke (2012) acknowledges there being individualism in communalism and vice versa. The methodology of Ubuntu (Elonga Mboyo, 2016; 2018), therefore, broadens the scope to illustrate how, even in Africa, fear and sel-scrutiny driven communalism and individualism (structure and agency) binaries insect in order to create four multi-perspectival ontological spaces within which interactions can be conceptualised. This contribution opens up the possibility for reflecting around contrasting similar and other forms of emergent epistemologies. 
Figure 1.

Fear and Self-scrutiny Methodology of Ubuntu/ Structuration framework (see Elonga Mboyo, 2016; 2018)

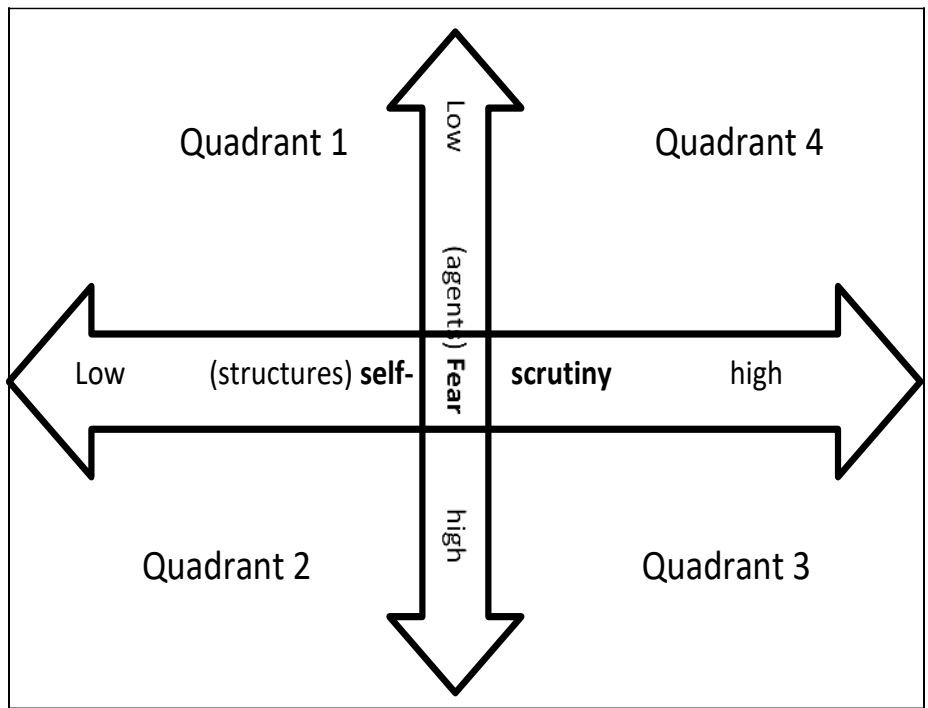

\section{How Can Epistemology Be Understood?}

'Put simply, in research, epistemology is used to describe how we come to know something; how we know the truth or reality' (Kivunja \& Kuyini, 2017). Epistemological pluralism is the affirmation of the 'existence of multiple knowledge or multiple ways of knowing and being' (Tesar \& Arndt, 2017, p. 666 cited in Andreotti et al., 2011). Such diversity has had an enduring tradition in educational leadership research. For example, instrumentalism as a type of research paradigm (Brundrett \& Rhodes, 2014), with its specific methodologies and methods, has enabled the development of instrumental knowledge (Ribbins \& Gunter, 2002). Ribbins and Gunter's review suggests other knowledges such as conceptual, humanistic, evaluative and critical. The body of literature on critical stance (Grogan \& Simmons, 2012) also 
speaks of variations such as critical race, feminism and decolonisation aimed at developing context-specific epistemologies.

As already stated, CRC subscribes to the diversity of knowledge. What remains to be articulated, however, is the shift from monolithic to pluralistic epistemologies without ascribing an impervious status to local epistemologies that cannot be divorced from de-compartmentalised ontologies. This is echoed when leadership practice is framed as consisting of valuing how 'social conditions or value postures that appear to share the same shape or meaning in different countries but actually consist of quite different elements' (Begley, 2000, p. 23). CRC knowledge is primarily subjective and although this would be portrayed by postmodernists incorrect as it takes away objectivity (Boghosssian \& Lindsay, 2018), human subjectivity in CRC is an unavoidable mediator/interface that turns common/specific (objective/ subjective) ontology into specific/common (subjective/ objective) epistemology and vice versa. The epistemology emerging from CRC then seeks to overcome the objective/ subjective binary by highlighting the shared situated-ness of human subjectivity in the ongoing production of context-specific epistemologies.

In this perspective, $21^{\text {st }}$ century technological advancements provide a viable avenue to reconsider the 'shared situated-ness' of human subjectivities. New forms of technology have propelled researchers and subjects of research (of any country) into a global web of different forms of subjectivities that do not only have to negotiate multiple identities and epistemologies but also adapt and use any of them to suit particular contexts. A CRC researcher's role therefore is to articulate processes of being, knowing and researching (as this article does) and demonstrating how professionals operationalise this 
paradigmic way of leading schools (second linked article). Other than $21^{\text {st }}$ century technological advancement, the shared situated-ness of human subjectivities as an epistemological interface can also be defended from the view that 'thinking [or knowing] without comparison is unthinkable' (Ragin, 1996, p. 74). Arguably, subjectivity as an embodied rationality generates knowledge through 'the other' and the wider phenomenon (Ozbilgin \& Vassilopoulou, 2018).

This means recognising that unlike in the territorially compartmentalised epistemologies when, for example, emotions were predicated to Africans and regarded as lower than objective knowledge compared to Western epistemologies (Lupton, 1998), emotions and feelings encapsulate knowledge even in western epistemologies (Goleman, 1998; Goleman et al., 2013), and even calling into question Hallinger's (2019) privileging of particular quantitative research methods rather than multi-perspectival for conclusive research claims. 'All knowledge is developed through the body' (Lupton, 1998, p. 36) which is also seen through the rise in emotional leadership literature (Crawford, 2007; Mills \& Niesche, 2014; Sachs \& Blackmore, 2010). It is essential that comparative research remains culturally sensitive to various embodied selves. Being attuned to evolving human subjectivity means that CRC researchers need to pay attention to shifts not only in the production of but also in the nature of the knowledge produced, in order to identify changing commonalities and differences.

\section{How Does a CRC Researcher Frame the Concept of Culture?}

Researchers opting for CRC from the outset will have to offer a rigorous discussion on issues related to conceptualisation about culture, the need to decolonise cultural dominance and essentialism while recognising the fluidity of human subjectivity. 
Although culture is complex and difficult to define, there is unanimous agreement that the concept refers to 'terms such as behaviour, values, norms, and basic assumptions' (Groseschl \& Doherty, 2000, p. 14) that arguably configure a unit's approach to knowing (epistemology) (Stephen, 2012) and the nature of reality (ontology). A unit here represents geographical boundary terms such as national and regional cultures, or distinctive patterns of behaviour within an industry, occupation or corporation (Pizam, 1993). Several layers and subcultures have also been identified among the geographical boundaries and within social units (Ofstede, 1994; Schein, 1985). Martin (1992), for example, makes a useful classification of group dynamics of culture as being about homogeneity, difference and ambiguity. For his part, Weiburst (1898) argues that culture can be taken as a historical entity, interpreted and manifested in contemporary times.

Despite the diversity of cultures, 'dominant research epistemologies have developed methods of initiating and assessing research in Africa where researchers fail to acknowledge the cultural preferences and practices of African people' (Higgs, 2012, p. 37). The radical move away from being 'cultural sabirs' (Bourdieu and Sayad 2015) has resulted in some writers (Dixon, 1977 for example) arguing for clear-cut cultural stances between Africans and Westerners with regard to axiology, time, activity, epistemology and logic. The adoption of this essentialist view of culture has the potential to reproduce a certain dominant insularity that the marginalised cultures were seeking to decolonise in the first place (Horsthemke \& Enslin, 2009). As already argued when making the case for CRC ontology, there are elements of individualism in community cultures and vice versa (Letseka, 2012). This should bring a researcher adopting CRC to prioritise unique cultural fluidity, that is ontologically and 
epistemologically embodied in a unique way in a given time and space (field), over substantive and intransitive cultural stereotypes (Collard, 2007). Far from considering everything about people's cultures as provisional and therefore negligible, CRC advocates for sensitivity to people's ongoing narratives about how they perpetuate and/ or redefine reality in their fields that can be meaningfully be described as 'zones of incompletion' (Elonga Mboyo, 2019a).

Such framing of subjectivities should lead to a position that does not favour one ontology, epistemology and culture over another. Doing so could translate into undue bias, which could lead to concealment of certain perspectives and voices that could be discordant with a chosen one-sided ontological and epistemological view. That means proceeding with one's research without making it either an exclusively objective or subjective ontological and (positivistic, phenomenological, critical theory and postmodern) epistemological enterprise. This is consistent with the experience of the world for many as a messy amalgamation rather than 'uncontaminated bundles' (Morrison, 2012, p. 25) of epistemologies. The call for 'a third methodological movement' (Gorard and Taylor, 2004) is particularly imperative in comparative studies. This sensitivity has to be demonstrated in the way that difference is cultivated (Kincheloe, 2001) in the choice of research approach(es) and other processes.

\section{Research Approach: Narratives}

Although CRC is an un-constraining attempt to decompartmentalise research, for practical purposes, it is likely that specific choices would need to be made with regard to research approach. Focusing on narratives here, among other approaches such as ethnography, grounded theory, visual research to name but a few (Briggs et al., 2012), the question that first emerges is: how can a single 
approach meet the CRC paradigm that is about bringing together various ontological, epistemological, cultural, etc., perspectives? Hence, the necessity to focus the discussion on the (comparative) validity of narratives within the overall paradigm. This section, therefore, discusses the multi-perspectival status of narratives in crosscontext (Europe and Africa) research that is exemplified in the second linked article.

\section{Contextual History}

Although postmodernism seems to have signalled a shift from meta or 'grand narratives' of humanity's cultural and technological progress, otherwise known as life histories (Loytard, 1984), to 'smallscale' personal narratives (life stories and auto-biographies), 'it is true that narratives and stories are part of the common currency of the day' (Goodson, 2013, p. 10). It is assumed that humanity started narrating and storytelling from time immemorial (Murray, 2008), with genres that 'deeply affect the shape and course of human thought' and action [our emphasis] (Bruner, 2012, p. 10). As a field of research inquiry into grand or small-scale narratives, a narrative approach to research is rather a recent enterprise (Clandinin et al., 2007). In Europe (West), the explosion of interest in narrative, in the last two decades or so, can be traced back to the works of Freud, Levi-Straus etc. and changing conceptions about language and text (Hyden, 2008). In Africa, its traditions have been long associated with storytelling (VanZanten, 2012). With a rich history in both continents, within which the research contexts of the second linked article are set, narrative research is arguably a comparatively consistent approach to study the two settings. 


\section{Definition}

Narrative research, in its simplistic form, can be viewed as a recital of facts (Allen, 2006). Beyond a supposedly disinterested transmission of factual accounts is the rational, emotional, subjective and intersubjective sense-making in which the person engages. On that basis, narrative research can be further regarded as concerned with accounting for and theorising on people's perspectives on their personal and professional lives (Newby, 2010). Hence, the attitude to narratives here is that which sees in them the generation of stories that are 'a portal through which a person enters the world and by which his (her) experience of the world is interpreted and made personally meaningful' (Caduri, 2013 cited in Clandinin \& Rosiek, 2007).

\section{CRC and Narratives}

Concepts such as 'small-scale' narratives and 'personal perspectives and meaningfulness' leave narrative inquiry open to the criticism that it is focused on 'the individual rather than on the social context' (Marshall \& Rossman, 2011, p. 153). It is not surprising that to overcome such a limitation some researchers would opt for a (multiple) case study approach that would enable diverse respondents' data triangulation, among others (Scott, 2007), and ultimately be able to compare. That said, a narrative research approach is understood to have multiple functions, including 'remember, argue, justify, persuade, engage, entertain, and even mislead an audience' (Riessman, 2008, p. $8)$. Besides the above functions of narratives, what has also received less emphasis is the reality that narrators use their narratives for comparative purposes. Narratives cannot be thought of outside comparison, which, as already stated, is fundamental to the sociological project (Smaje, 1997). Commenting on the nature of research in Africa, Higgs (2012, p. 44) advises researchers to take 
account of 'the double role of individuals in African societies' to highlight a certain degree of oscillation from subjective to objective (individual to collective), and vice versa, ontologies, epistemologies and cultures in order to generate critically decolonising perspectives on educational practices.

The danger then of reducing narratives to the linguistic act is that of missing out on other communicative media, such as facial expressions, gestures, postures, pauses and so on (Heslep, 2001). Despite the failure to capture everything, researchers and readers can find consolation in that an exact record will remain elusive even to practitioners and, as Bold (2012) argues, we must look at the stories as tentative (comparative) representations. Such representations, according to Lewis (2011), are powerful enough to shape identity, self and practice without necessarily being the sole author of life experiences that depend on many other factors (Murray, 2008).

This is almost saying that we can study the habitus of school leadership practice without pretending to capture experiences 'in the very movement of their accomplishment' (Bourdieu, 1977, p. 3). It does not mean doubting the authenticity of informants' stories but perhaps ensuring that the conditions are right to engage with participants in the (co-)authorship of identities and practice and give some epistemological credence to the study's findings (Caduri, 2013). Above all, what this section has highlighted, whatever the research approach adopted, is the need to recognise, discuss and apply cultural idiosyncrasies of a single (or more) research approach within the CRC paradigm. This has implications for cultivating difference in the deployment of methods for data gathering. 


\section{Methods}

Whether one is engaged in a narrative approach or not, there are two main possibilities that a CRC researcher can rely on to augment multi-perspective: multi-method and mix-and-match or mixed method. A multi-method approach means engaging in 'data collection using two or more [our emphasis] methods from the same paradigm' (Hickman, 2015, p. 42). A mix-and-match approach, however, employs qualitative and quantitative methods in an effort to overcome a distinctive paradigm approach to research (Morrison, 2012). Hence, statistical survey data may be combined with data from interviews and/ or focussed group discussions. This also shows the need to move 'away from the perhaps more traditional approaches to educational (leadership) research to 'alternative methodologies and methods' (Todd, 2018, p. 50) that are 'slightly riskier alternatives' (Showunmi \& Fox, 2018, p. 3).

It could be argued, however, that it is not an absolute necessity to use either multi-method or mix-and-match, if difference can be cultivated elsewhere during other research processes. In other words, procedural flexibility needs to be compensated by a degree of diversified elasticity, so that the freedom to deploy a single method may constitute a middle shift to diversify analytical processes that ignite other research methods in future development of a given research project. For example, the second linked article uses only narrative interviews (better described as 'leadership conversations') regarded through different dimensions or layers of data analysis that cultivated 'difference'. As shall be discussed in the second linked article, the analysis delivered both 'objective' and 'subjective' knowledges and how participants overcome those binaries. This result is testament to CRC approach. While it starts off with an all encompassing beyond binary approach, its outcome may show traces 
of dualism and other ontological features determined by specific and cross-context stories of actions that give rise to theories of context. This, in itself, is a middle shift for future research in the sense that it is now possible to scale up the research with a larger sample using a survey tool to build levels 1 - 4 statistical tests about 'objective' school leadership knowledge as recommended by Hallinger (2019), to be followed up with interviews in order to extract the sense making or subjective knowledge that explains the objective data within CRC paradigm.

That said, a CRC researcher must demonstrate how cultural preferences in eliciting epistemological pluralism are embedded in a chosen method, multi-method or mix-and-match, whether traditional or its (riskier) alternative (Showunmi \& Fox, 2018; Todd, 2018).

\section{Constituencies}

\section{Various groups of people}

The need for research validity requires that data be triangulated theoretically, using various research methods and/ or participants (Bush, 2012). Floyd (2012) argues that validity in a narrative research approach is better measured by looking at the complementarity instead of the triangulation of narrative extracts. This can be verified using a grounded theory tool called 'goodness of fit' (Payne, 2007, p. 84) to see how thematised stories of different individuals within a single constituency of participants fit to develop a contextual and cross-contextual narrative/ theory.

On the educational leadership conceptual side, underpinning the view that research findings need to be triangulated by different constituencies of participants is the growing recognition that school 'leadership is more than the exercise of a positional [my italics] role' of one person (Todd, 2018, p. 51), and that it is a shared and relational 
activity. Hence, Day et al. (2001) used a multi-perspective methodology that consisted of collecting data from different stakeholders (constituencies), such as head teachers, teachers, students and parents, to build a 'wider picture' of a school leader, as an alternative to autobiographical studies focusing only on head teachers' views.

That said, part of the sensitivity required by a CRC researcher is understanding what the perspectives of multiple constituents mean from a given cultural setting. For example, the triangulation argument (Bush, 2012) seems to convey a cultural assumption where multiple perspectives corroborating a given finding are a cross-examined subtotal of views of different constituents. However, the idea of community (as in individuals with multiple perspectives) is not simply a subtotal of individuals in some cultures. For example, the 'double role of individuals in Africa' (Higgs, 2012, p. 44) means that multiple perspectives can be obtained from a single individual. Higgs makes the affirmation without providing the clues to aid analysis. The research on which the second linked article is based exemplifies this double role of individuals when a participant said, 'my school is the $X$ (country in question) in miniature' and 'unlike other schools where teachers go in with begging bowls, this school works hard aiming for ethical excellence'. A CRC researcher is encouraged to tap into this form of triangulation, that is arguably not exclusive to (African) community-oriented cultures, and meet the complementary criteria (Floyd, 2012) for narrative validity and develop contextual, national and even cross-context theories of action (Goodson, 2013).

\section{Analytical Perspectives}

A CRC study can also be described as multi-perspective, based on the analytical approaches it cultivates. A single thematic approach 
can be used to identify multiple perspectives of different constituents on a single issue. However, different layers of analytical strategies can be used on data from one kind of constituent, in order to uncover different voices and meanings. Within the narrative approach, and consistent with CRC, Goodson (2013, p.5), for example, calls for the need 'to embrace stories of action within theories of context'. Vandermause et al. (2014) demonstrated this by starting off with a postpositivist analytical approach to abstract similarities and differences in the texts they analysed. This level of analysis resulted in establishing themes that defined the actions and behaviours of research participants.

Using 'an interpretative phenomenological approach (IPA) to identify overlapping patterns in the texts in a search for ontological meaning', Vandermause et al. (2014, p. 674) delved further into extracted themes to provide a different kind of knowledge. While the extracted themes are subjective knowledge based on stories of action, the ontological meanings (derived through IPA) can be referred to using Ponte's (2010) terminology as 'objective' mediated knowledge.

The exercise of weaving themes 'together for a coherent crosscontextual narrative' (Saldana, 2009) or 'goodness of fit' (Payne, 2007) and revaluating them to distil ontological meanings (Vandermause et al., 2014) or theories of context shaping various stories of actions (Goodson, 2013) is not an attempt to create incommensurate ontological and epistemological binaries (of educational leadership practices). Whatever the onotological and epistemological theories of contexts, they remain contextually unique and become the basis for undertading further practice-based analysis to establish how practitioners rise above binaries in order to develop context-specific decolonising stories of school leadership actions. 


\section{Conclusion}

The decolonising approach to research in educational leadership theory and practice of indigenous people (Africans in this case) has been the focus of this initial linked article. While others might elect the territorial approach (e.g. Khalifa et al., 2018), this article has sought to explore the viability of an instrumental/comparative research approach consistent with Smith's (1999) view that decolonisation is not a rejection of Western notions. CRC has, therefore, been proposed as an ontological, epistemological and cultural cornerstone for research initiatives that can take different approaches including the narrative one whose multi-perspectival design has been demonstrated and rehearsed here. The second linked article takes this further to theorise on how specific researched headteachers have attempted to operationalise this decolonising comparative approach to educational leadership in a given African context as compared to another in the West.

The commentaries and (possible) empirical research studies in reaction to this initial linked article could take several approaches that may (or not) include a critique and/or defence of CRC as a viable approach to decolonising educational leadership research in Africa. They may, however, take the form of literature reviews as well as empirical studies that subscribe (or not) to one of Zoogah and Nkomo's (2013) territorial, sentimental, symbolic and instrumental/comparative approaches to leadership and management research in (a given context in) Africa while bearing in mind the pertinence of decolonising educational leadership theories and practices. 


\section{References}

Allen, C. (2006). Narrative research. Nurse Researcher, 13(3), 4-6.

Andreotti, V., Ahenakew, C. \& Cooper, G. (2011) Epistemological pluralism: Ethical and pedagogical challenges in higher education. AlterNative: An International Journal of Indigenous Scholarship 7(1), 40-50.

Begley, P. (2000) Cultural isomorphs of educational administration: reflections on Western-centric approaches to values and leadership. Asia Pacific Journal of Education, 20(2), 23-33.

Bhaskar, R. (1989). Reclaiming reality. London: Verso.

Boghossian, P. \& Lindsay, J. (2018). Peter Boghossian-What comes after postmodernism? Educational Philosophy and Theory, 50(14), 1346-1347.

Bold, C. (2012). Using narrative in research. London: Sage.

Bourdieu, P. (1997). Outline of a theory of practice. Cambridge: Cambridge University Press.

Bourdieu, P. \& Sayad, A. (2015). Uprooting. Cambridge: Polity.

Briggs, A., Coleman, M., \& Morrison, M. (eds). (2012). Research methods in educational leadership and management. ( $3^{\text {rd }}$ ed.). London: Sage.

Brundrett, M., \& Rhodes, C. (2014). Researching educational leadership and management. London: Sage.

Bruner, J. (2012). What psychology should study. International Journal of Educational Psychology, 1(1), 5-13.

Burrell, G., \& Morgan, G. (1979). Sociological Paradigms and Organisational Analysis. Aldershot: Gower.

Bush, T. (2012). Authenticity in research: Reliability, validity and triangulation. In A. R. J. Briggs, M. Coleman \& M. Morrison (Eds.), Research Methods in Educational Leadership and Management, (3 ${ }^{\text {rd }}$ ed.) (pp. 75-89). London: Sage. 
Caduri, G. (2013). On the epistemology of narrative research in education. Journal of Philosophy of Education, 47(1), 37-52.

Carroll, K.K. (2014). An introduction to African-centered sociology: worldview, epistemology, and social theory. Critical Sociology, 40(2), 257-270.

Clandinin, D. J., Pushor, D., \& Orr, A. M. (2007). Navigating sites for narrative inquiry. Journal of Teacher Education, 58(1), 21-35.

Clandinin, J., \& Rosiek, J. (2007). Mapping a landscape of narrative inquiry. In D. Clandinin (ed.) Handbook of Narrative Inquiry: Mapping a Methodology. Thousand Oaks, CA: Sage Publications.

Coleman, D., \& Rowthorn, R. (2004). The economic effects of immigration into the United Kingdom. Population and Development Review, 30(4), 579-624.

Coleman, M. (2012). Interviews. In A. R. J. Briggs, M. Coleman \& M. Morrison (Eds.), Research Methods in Educational Leadership and Management ( $3^{\text {rd }}$ ed.) (pp.250-265). London: Sage.

Collard, J. (2007). Constructing theory for leadership in intercultural contexts. Journal of Educational Administration, 45(6), 740-755.

Crawford, M. (2007). Rationality and emotion in primary school leadership: an exploration of key themes. Educational Review, 59(1), 87-98.

Creswell, J. (2005). Research design ( $2^{\text {nd }}$ ed.). London: Sage.

Creswell, J. (2009). Research design ( $3^{\text {rd }}$ ed.). London: Sage.

Crossley, M. \& Watson, K., (2003). Comparative and international research in education: Globalisation, context and difference. London: RoutledgeFalmer.

Dabashi, H. (2013). Being a muslim in the World. New York: Palgrave Macmillan.

Day, C., Harris, A., \& Hadfield, M. (2001). Grounding knowledge of schools in stakeholder realities: A multi-perspective study of 
Elonga Mboyo (2021). The Viability of Comparative Research Concept as a

effective school leaders. School Leadership and Management, 21(1), 19-42.

Denzin, N. K. \& Lincoln, Y.S (eds) (2005) The Sage handbook of qualitative research ( $3^{\text {rd }}$ ed.). Thousand Oaks, Sage.

Dixon, V. J. (1977). African-oriented and Euro-American-oriented worldviews: research methodologies and economics. The Review of Black Political Economy, 7(2), 119-156.

Eacott, S. (2019). Starting points for a relational approach to organizational theory: An overview. Research in Educational Administration \& Leadership, 4 (1), 16-45.

Elonga Mboyo, J. P. (2016). Africa through structuration theory: Outline of the FS (fear and self-scrutiny) methodology of Ubuntu ( $2^{\text {nd }}$ ed.). Cameroon: Langaa RPCIG.

Elonga Mboyo, J. P. (2018). Framing ethical isomorphs in educational leadership: A sociological approach. International Journal of Leadership in Education, 21(1), 122-133.

Elonga Mboyo, J. P. (2019a). A nuanced critical realist approach to educational leadership policy and practice development: redefining the nature of practitioners' agency. Educational Philosophy and Theory, 51(8), 815-828.

Elonga Mboyo, J. P. (2019b). Moving forward amidst the swirls: Reframing the relational approach as a step 'beyond' leadership. Research in Educational Administration \& Leadership, $4(1), 47-79$.

Everett, J. (2002). Organizational research and the praxeology of Pierre Bourdieu. Organizational Research Methods, 5(1), 56-80.

Floyd, A. (2012). Narrative and life history. In A. R. J. Briggs, M. Coleman \& M. Morrison (Eds.), Research Methods in Educational Leadership and Management, (3 ${ }^{\text {rd }}$ ed.) (pp. 223-235). London: Sage. 
Goleman, D. (1998). What makes a leader? Harvard Business Review.

Goleman, D., Boyatzis, R., \& McKee, A. (2013). Primal leadership: Unleashing, the power of emotional intelligence. Boston, Massachusetts: Harvard Business Review Press.

Goodson, I. (2013). Developing narrative theory: Life histories and personal representations. London: Routledge.

Guba, E. G. \& Lincoln, Y. S. (2005). Paradigm controversies, contradictions, and emerging confluences. In N. K Denzin and Y. S. Lincoln (eds). The Sage Handbook of Qualitative Research (3 ${ }^{\text {rd }}$ ed.,) (pp. 191-215). Thousand Oaks: Sage.

Grogan, M., \& Simmons M. C. J. (2012). Taking a critical stance in research. In A. R. J. Briggs, M. Coleman \& M. Morrison (eds.), Research Methods in Educational Leadership and Management ( $3^{\text {rd }}$ ed.) (pp. 29-45). London: Sage.

Groseschl, S., \& Doherty, L. (2000). Conceptualising culture. Cross Cultural Management: An International Journal, 7(4), 12-17.

Hallinger, P. (2018). Surfacing a hidden literature: A systematic review of research on educational leadership and management in Africa. Educational Management Administration \& Leadership, $46(3), 362-384$.

Hallinger, P. (2019). A systematic review of research on educational leadership and management in South Africa: Mapping knowledge production in a developing society. International Journal of Leadership in Education, 22(3), 315-333.

Harris, A. \& Jones, M. (2017). Leading in context: putting international comparisons into perspective, School Leadership \& Management, 37(5), 431-433.

Heslep, D. R. (2001). Habermas on communication in teaching. Educational Theory, 51(2), 191-207. 
Hickman, H. E. (2015). Mixed methods research. Nursing Standards, 29(32), 41-47.

Higgs, P. (2012). African philosophy and the decolonisation of education in Africa: Some critical reflections. Educational Philosophy and Theory, 44(2), 37-55.

Hillage, J., Pearson, R., Anderson, A., \& Tamkin, P. (1998). Excellence in research on schools. London: Department of Education and Employment.

Hofstede, G. (1994) Cultures and organizations. London: Harper Collins Publishers.

Horsthemke, K., \& Enslin, P. (2009). African philosophy of education: The price of unchallengeability. Studies in Philosophy and Education, 28(3), 209-222.

Hyden, H. L. (2008). Narratives in illness: A methodological note. Qualitative Sociology Review, 4(3), 49-58.

Jakonen, J. P. (2009). Beyond postmodern spirituality: Ken Wilber and the integral approach. Scripta Instituti Donneriani Aboensis, 21, 92-109.

Khalifa, M.A., Khalil, D., Marsh, T.E.J., \& Halloran, C. (2018). Towards an indigenous, decolonizing school leadership: A literature review. Educational Administration Quarterly, 55(4), 571-614.

Kincheloe, J. L. (2001). Describing the bricolage: Conceptualizing a new rigor in qualitative research. Qualitative Inquiry, 7(6), 679-692.

Kivunja, C. \& Kuyini, A. (2017). Understanding and applying research paradigms in educational contexts. International Journal of Higher Education, 6(5), 26-41.

Kuhn, T. S. (1962). The structure of scientific revolutions. University of Chicago Press: Chicago.

Lewis, J. P. (2011). Storytelling as research / research as storytelling. Qualitative Inquiry, 17(6), 505-510. 
Letseka, M. (2012). In defence of Ubuntu. Studies in Philosophy and Education, 31(1), 47-60.

Lupton, D. (1998). The emotional self. London: Sage

Lyotard, J. F. (1984). The postmodern condition: A report on knowledge. Vol. 10. Minnesota: University of Minnesota Press.

Marshall, C., \& Rossman, S. B. (2011). Designing qualitative research (5 $5^{\text {th }}$ ed.). Thousand Oaks, CA: Sage.

Marshall, J. (2014). Introduction to comparative and international Education. London: Sage.

Martin, J. (1992). Cultures in organizations: Three perspectives. Oxford University Press.

Métais, L. J. (2001). Approaches to comparing education systems. In K. Watson (ed.), Doing Comparative Education Research: Issues and Problems (pp.197-209). Oxford: Symposium Books.

Mills, M., \& Niesche, R. (2014). School reform and the emotional demands of principals: Lorna's story. School Leadership and Management, 34(2), 120-135.

Morgan, D. L. (2007). Paradigms lost and pragmatism regained: Methodological implications of combining qualitative and quantitative methods. Journal of Mixed Methods Research, 1(1), 48-76.

Morgan, G. (2006). Images of organisation. London: Sage.

Morrison, M. (eds.), Research methods in educational leadership and management, (3 $3^{\text {rd }}$ ed.) (pp. 223-235). London: Sage.

Morrison, M. (2012). Understanding methodology. In A. R. J. Briggs, M. Coleman \& M. Morrison (Eds.), Research Methods in Educational Leadership and Management, (3 ${ }^{\text {rd }}$ ed.) (pp.14-28). London: Sage. 
Murray, M. (2008). Narrative psychology. In A. J. Smith (ed.), Qualitative Psychology, A Practical Guide to Research Methods (2 ${ }^{\text {nd }}$ ed.) (pp.111-132). London: Sage.

Newbury, M., Gallant, A., \& Riley, P. (2013). Emotions in schools: Understanding how the hidden curriculum influences relationships, leadership, teaching and learning. Bingley: Emerald.

Newby, P. (2010). Research methods for education. Harlow: Pearson Education.

Outhwaite, D. (2018). Identifying the research process to analyse the adoption of the International Baccalaureate's Diploma Programme in England. Management in Education, 32(10), 13-18.

Ozbilgin, M. \& Vassilopoulou, J. (2018). Relational methods in organization studies: A critical overview. In M. Ciesielska, \& D. Jemielniak, (eds). Qualitative Methodologies in Organization Studies: Volume I Theories and new Approaches. (pp. 151-177). Palgrave McMillan.

Payne, S. (2007). Grounded theory (pp. 65-86). In Lyons E. \& Coyle A (eds) Analysing Qualitative Data in Psychology. London: Sage.

Pizam, A. (1993). Managing cross-cultural hospitality enterprises' in the international hospitality industry. In P. Jones, \& A. Pizam, (eds.). The name of the Book???London: Pitman Publishing.

Poloma, A. \& Szelényi, K. (2018). Coloniality of knowledge, hybridisation, and indigenous survival: Exploring transnational higher education development in Africa from the 1920s to the 1960s. Compare: A Journal of Comparative and International Education, DOI: 10.1080/03057925.2018.1445962

Ponte, P. (2010). Postgraduate programmes as platforms: Coming together and doing research for a common moral purpose. In A. Campbell, \& S. Groundwater-Smith (Eds.), Connecting Inquiry and Professional Learning in education: International 

6(3), September 2021, 554-584

Perspectives and Practical Solutions (pp.68-82). London: Routledge.

Ragin, C. C. (1996). The distinctiveness of comparative social science. In A. Inkeles, \& M. Sasaka, (1996). Comparing Nations and Cultures: Readings in a Cross-Disciplinary Perspective. (pp. 74-89). London: Pretice-Hall International.

Rhodes, L., \& Brundrett, M. (2010). Leadership for learning. In T. Bush, L. Bell \& D. Middlewood (eds.), The Principles of Educational Leadership and management ( $2^{\text {nd }}$ ed.) (pp. 153-175). London: Sage. Ribbins, P., \& Gunter, H. (2002). Mapping leadership studies in education: towards a typology of knowledge domains. Education Management \& Administration, 30(4), 359-385.

Riessman, K. C. (2008). Narrative methods for the human sciences. London: Sage.

Sachs, J., \& Blackmore, J. (2010). You never show you can't cope: Women in school leadership roles managing their emotions. Gender and Education, 10(3), 265-279.

Saldaña, J. (2009). The coding manual for qualitative researchers. Thousand Oaks, CA: Sage.

Samier, E. (2017). Towards a postcolonial and decolonising educational administration history. Journal of Educational Administration and History, 49(4), 264-282.

Schein, E. (1985). Organizational vulture and leadership. London: JosseyBass Ltd.

Scott, D. (2012). Research design: Frameworks, strategies, methods and technologies. In A. R. J. Briggs, M. Coleman \& M. Morrison (eds.), Research Methods in Educational Leadership and Management, (3 ${ }^{\text {rd }}$ ed.) (pp. 106-121). London: Sage

Showunmi, V. \& Fox, A. (2018). Editorial: Exploring research methods for educational leadership. Management in Education, 32(1), 3-5. 
Slawecki, B. (2018). Paradigms in qualitative research. In M. Ciesielska, \& D. Jemielniak, (eds). Qualitative Methodologies in Organization Studies: Volume I Theories and new Approaches. (pp. 7-26) Palgrave McMillan.

Smaje, C. (1997). Not just a social construct: Theorising race and ethnicity. Sociology, 31(2), 307-327.

Smeyers, P., \& Smith, R. (2014). Understanding education and educational research. Cambridge: Cambridge University Press.

Smith, L. (1999). Decolonising methodologies: Research and indigenous peoples. London: Zed Books.

Spillane, J. P. \& Hunt, B. R. (2010). Days of their lives: A mixedmethods, descriptive analysis of the men and women at work in the principal's office. Journal of Curriculum Studies, 42(3), 293331.

Springgay, S. \& Truman, S. E. (2017). A transmaterial approach to walking methodologies: Embodiment, affect, and a sonic art performance. Body and Society, 23(4), 27-58.

Stake, E. R. (2006). Multiple case study analysis. London: The Guilford Press.

Steiner-Khamsi, G. (2016). New directions in policy borrowing research. Asia Pacific Education Review, 17, 381-390.

Stephens, D. (2012). The role of culture in interpreting and conducting research. In A. R. J. Briggs, M. Coleman \& M. Morrison (eds.), Research Methods in Educational Leadership and Management, (3 $3^{\text {rd }}$ ed.) (pp.46-60). London: Sage.

Tesar, M., \& Arndt, S. (2017). Cross-cultural complexities of educational policies. Policy Futures in Education, 15(6),665-669.

Todd, L. (2018). Imagining methodology: Doing educational leadership research differently. Management in Education, 32(1), $50-52$. 
Udefi, A. (2014). The rationale for an African epistemology. Canadian Social Science, 10(3), 108-117.

Vandermause, R., Leiker, B. C., \& Fritz, R. (2014). Research education: Findings of a study of teaching-learning research using multiple analytical perspectives. Journal of Nursing Education, 53(12), 673-677.

VanZanten, S. (2012). Introduction: African narrative and the Christian tradition. Christianity and Literature, 61(3), 369-376.

Weaver, J. E. \& Snaza, N. (2017). Against methodocentrism in educational research. Educational Philosophy and Theory, 49(11), 1055-1065.

Weibust, P. (1989). Tradition as process: Creating contemporary tradition in a rural Norwegians school and community. International Journal of Qualitative Studies in Education, 2(2), 107122.

Zoogah, B. D., \& Nkomo, S. (2013). Management research in Africa, past, present and future. In R. T. Lituchy, B. J. Punnett, \& B. B. Puplampu (eds.), Management in Africa, Macro and Micro Perspectives (pp.9-31). London: Routledge.

\footnotetext{
About the author:

Jean Pierre Elonga Mboyo is Senior Lecturer at Teesside University. $\mathrm{He}$ teaches an undergraduate and postgraduate courses and researches educational leadership.

Email: jp.elonga@tees.ac.uk

Twitter: @jpelonga
} 